\title{
Development of the Gastrointestinal Mucosal Barrier: Changes in Phospholipid Head Groups and Fatty Acid Composition of Intestinal Microvillus Membranes from Newborn and Adult Rats
}

\author{
SHU-HEH W. CHU AND W. ALLAN WALKER \\ Combined Program in Pediatric Gastroenterology and Nutrition at Harvard Medical School (Children's Hospital \\ and Massachusetts General Hospital) and Department of Pediatrics, Harvard Medical School,
}

Boston, Massachusetts 02115

\begin{abstract}
Phospholipids in microvillus membrane (MVM) prepared from the proximal small intestine of newborn (less than $24 \mathrm{~h}$ of age) and adult rats were characterized to determine if differences in composition existed. Our hypothesis is that developmental differences in composition of the MVM may account for mucosal barrier differences to microorganisms and antigens during the perinatal period. Lipid analysis showed that both cholesterol and total phospholipids, per $\mathrm{mg}$ of membrane protein, were much higher in the newborn MVM than the adult, but the molar ratio of these two lipid classes remained unchanged. Increased phosphatidylcholine and decreased phosphatidylinositol levels were found in the newborn MVM compared to the adult. In addition, the major difference in fatty acid composition of total lipid extracts and three major membrane phospholipids, phosphatidylcholine, phosphatidylethanolamine, and phosphatidylinositol appeared to be an increased ratio of palmitate (16:0) to stearate $(18: 0)$ and of oleate $(18: 1)$ to linoleate $(18: 2)$ in the newborn. These data suggest that changes in the proportion of phospholipid polar head groups and fatty acyl groups as well as changes in the amount of total phospholipids and cholesterol exist in the newborn MVM. These observations are consistent with differences in MVM fluidity previously noted and may help explain the increased uptake of antigens and other mucosal barrier defects in the newborn intestine. (Pediatr Res 23: 439-442, 1988)
\end{abstract}

Abbreviations

MVM, microvillus membrane

HEPES, N-2-hydroxyethylpiperazine $\mathrm{N}^{\prime}$-2-ethanesulfonic acid

During postnatal development, the intestinal MVM undergoes dramatic changes $(1,2)$. One of the major compositional changes is an increased lipid to protein ratio in the MVM of the immature

Received September 28, 1987; accepted December 17, 1987.

Correspondence Dr. Shu-heh W. Chu, Combined Program in Pediatric Gastroenterology and Nutrition, Children's Hospital, 300 Longwood Avenue, Boston, MA 02115.

Supported in part by the USPHS NIH Grants DK-33506, DK-37521, and HD12437. newborn intestine compared to that of the adult as shown by Pang et al. (3) in rabbits. This change in the immature intestine is associated with an increased membrane fluidity and with an increased membrane disorder $(3,4)$ as well as an increased membrane permeability to luminal macromolecules (5). Conceivably, alterations in interactions between lipid and protein or lipid and lipid molecules may be responsible for these membrane barrier disruptions.

The phospholipid bilayer constitutes the major and basic structural component of MVM. It may greatly influence not only the biophysical but also biochemical properties of the MVM, a major component of the intestinal mucosal barrier. In general, phospholipid alterations may directly affect membrane fluidity (6), the activity of membrane-bound enzymes $(7,8)$, membrane transport systems (9), receptor binding events $(10$, 11 ), and protein attachment to membranes (12). In addition, the components of phospholipids (polar head groups, fatty acids, and diacylglycerols) may play an individual role in cation binding and release (13) and in second messenger systems $(10,11,14)$. However, the role of phospholipid in the development of the intestinal surface structure and function is not well defined, and phospholipid fatty acid composition has not been previously studied in the MVM of the newborn intestine.

In order to determine specific differences in MVM phospholipids between the immature and mature small intestine that may play a potential role in development of the mucosal barrier, the composition of MVM phospholipids and the fatty acid pattern in the total lipid extract as well as in major membrane phospholipid classes were characterized in MVM prepared from newborn and adult rats. The results indicate that both polar head groups and fatty acyl groups of phospholipids were altered in the newborn intestine and suggest that changes in MVM phospholipid molecules might, partially, contribute to the altered membrane fluidity and membrane permeability noted in newborns.

\section{MATERIALS AND METHODS}

Animals. Sprague-Dawley rats of CD strain (Charles River Breeding Laboratories, Wilmington, MA) were used. Pregnant rats were purchased on the 16- to 18-day gestation to provide the newborn rats to be studied (less than $24 \mathrm{~h}$ after birth). Female rats weighing 200-250 g were used for the preparation of adult MVM. Animals were housed in an animal room with a 12-h light-dark cycle and fed Purina Rat Chow (St. Louis, MO) and water ad libitum. 
MVM preparations. MVM was prepared by $\mathrm{MgCl}_{2}$ precipitation according to a modification of the method of Hauser et al. (15). All steps in the preparation were carried out at $4^{\circ} \mathrm{C}$. Nonfasted animals were killed by decapitation between 0900 and $1000 \mathrm{~h}$. The entire small intestine was removed and divided into proximal and distal halves. The intestinal segments were rinsed with normal saline $(0.9 \% \mathrm{NaCl})$ to remove the luminal contents. Only the proximal half was used in this study. The mucosa of adult intestine was scraped. The mucosa of newborn intestine was obtained by briefly homogenizing the whole proximal intestine in $0.9 \% \mathrm{NaCl}$ and passing it through a $170-\mu$ nylon mesh to remove intestinal smooth muscle. Mucosal scrapings of the adult and the crude mucosal homogenate of the newborn were then homogenized in a buffer ( $\mathrm{pH} 7.4)$ containing $500 \mathrm{mM}$ mannitol, $10 \mathrm{mM}$ HEPES, and $5 \mathrm{mM}$ EGTA for $5 \mathrm{~min}$. The homogenates were diluted with distilled water to six times its original volume before filtering through a $40-\mu$ nylon mesh to exclude large particulate material. $\mathrm{MgCl}_{2}(1 \mathrm{M})$ was added to the filtrate to make a final concentration of $10 \mathrm{mM}$. After mixing for $15 \mathrm{~min}$, the filtrate was centrifuged at $5000 \times \mathrm{g}$ for $15 \mathrm{~min}$ to clear cellular debris and other organelles. The supernatant was centrifuged at $28,000 \times g$ for 30 min to collect the crude MVM. The crude MVM was then resuspended in a buffer ( $\mathrm{pH} 7.4$ ) containing $100 \mathrm{mM}$ mannitol, $10 \mathrm{mM}$ HEPES, and $5 \mathrm{mM}$ EGTA, and recentrifuged under the same conditions. The final membrane preparation was suspended in $10 \mathrm{mM}$ Tris- $\mathrm{HCl}$ buffer (pH 7.4) containing $5 \mathrm{mM}$ EGTA, and stored at $-20^{\circ} \mathrm{C}$ for further analysis.

Enzyme assays. Purity of the membrane preparation was estimated by enrichment of lactase activity (16) for the newborn and sucrase activity (17) for the adult. Alkaline phosphatase was determined with $p$-nitrophenylphosphate (18). Protein was determined by the method of Lowry et al. (19) using bovine serum albumin as a protein standard.

Lipid analysis. Lipid was extracted from MVM according to the method of Folch et al. (20). Cholesterol was determined by the method of Rudel and Morris (21). Individual phospholipid classes were separated by two-dimensional thin-layer chromatography on silica gel $\mathrm{H}$ plates according to the method of Turner and Rouser (22) with $\mathrm{CHCl}_{3} / \mathrm{CH}_{3} \mathrm{OH} / 28 \% \mathrm{NH}_{4} \mathrm{OH}$ (65:25:5, $\mathrm{vol} / \mathrm{vol})$ and chloroform/acetone/methanol/acetic acid/water (3:3:1:1:0.5, vol/vol). Phospholipid phosphorus was determined by the method of Bartlett (23). Fatty acid composition in total lipids and individual phospholipids was determined by the gasliquid chromatography as previously described (24).

\section{RESULTS}

Changes in $M V M$ enzymes. The purification of both newborn and adult MVM preparations was in the range of 10- to 15-fold, based on the specific activity of lactase and sucrase, respectively. As shown in Table 1, these two membrane preparations exhibited the typical enzyme pattern of intestinal development-an absence of sucrase activity in the newborn and a marked decrease in lactase activity in the adult. These data are consistent with the fact that during the development of the rat small intestine, the appearance of sucrase activity begins in the $2 \mathrm{nd}$ wk of life, whereas the decline in lactase activity occurs after weaning (1). Table 1 also shows that the activity of alkaline phosphatase in the newborn MVM was decreased to approximately $46 \%$ of the adult level. These enzyme changes suggest that the MVM phospholipids prepared from newborn and adult rats were associated with different patterns of MVM proteins.

Changes in MVM lipid contents. Lipid analysis (see Table 1) indicates that MVM contents of both cholesterol and total phospholipids, expressed per unit weight of membrane protein, were much higher in the newborn than the adult. However, there was no significant difference in the molar ratio of cholesterol to phospholipid between newborn and adult MVM. Herein the values were estimated to be 1.25 and 1.20 for the newborn and adult membranes, respectively. These values are comparable to previously reported value of 1.26 for the adult rat intestine (25).

Changes in MVM phospholipid composition. The phospholipid composition of these two MVM is given in Table 2. In a manner similar to adult MVM, the major phospholipid classes in newborn MVM were found to be phosphatidylcholine and phosphatidylethanolamine. These two phospholipid classes constituted approximately $60-70 \%$ of total phospholipids. Although all the phospholipid classes present in the adult MVM were detected in the newborn, the phospholipid composition was found to be significantly different between immature and mature membranes. The proportion of phosphatidylcholine was increased from $34.6 \%$ in the adult to $44.4 \%$ in the newborn, whereas the proportion of phosphatidylinositol was decreased from $7.4 \%$ in the adult to $3.6 \%$ in the newborn.

Changes in total lipid fatty acid pattern of MVM. To characterize membrane fatty acid changes in the newborn and adult intestine, fatty acids were analyzed in total lipid extracts of MVM. The results are given in Table 3. With respect to saturated fatty acids, the ratio of palmitate (16:0) to stearate $(18: 0)$ in the newborn was three times of that in the adult. In addition, the proportion of myristate (14:0) in the newborn was higher than that in the adult. With respect to the unsaturated fatty acids, the ratio of oleate $(18: 1)$ to linoleate $(18: 2)$ in the newborn was two times that in the adult. However, neither the proportion of total

Table 1. Characteristics of microvillus membranes prepared from the newborn and adult rat proximal small intestine*

\begin{tabular}{|c|c|c|}
\hline & \multicolumn{2}{|c|}{ Microvillus membrane } \\
\hline & Newborn & Adult \\
\hline Enzyme activity & \multicolumn{2}{|c|}{$\begin{array}{l}\text { Substrate hydrolyzed, } \\
\mu \mathrm{mol} / \mathrm{min} / \mathrm{mg} \text { protein }\end{array}$} \\
\hline Lactase & $1.22 \pm 0.11 \uparrow$ & $0.12 \pm 0.01$ \\
\hline Sucrase & ND‡ & $1.45 \pm 0.20$ \\
\hline Alkaline phosphatase & $2.72 \pm 0.19 \dagger$ & $5.93 \pm 0.32$ \\
\hline Lipids & \multicolumn{2}{|c|}{$\mu g / m g$ protein } \\
\hline Cholesterol & $210.0 \pm 13.7 \dagger$ & $111.7 \pm 4.9$ \\
\hline Phospholipid & $317.5 \pm 28.6 \dagger$ & $193.3 \pm 8.2$ \\
\hline & \multicolumn{2}{|c|}{$\mathrm{mol} / \mathrm{mol}$} \\
\hline Cholesterol/phospholipid & $1.25 \pm 0.15$ & $1.20 \pm 0.11$ \\
\hline
\end{tabular}

* Values are means $\pm S E$ of four membrane preparations. The protein yield for both newborn and adult membrane preparations was about 2$3 \%$, lactase yield for the newborn was about $20-25 \%$, and sucrase yield for the adult was about $25-30 \%$.

$\dagger$ Significantly $(p<0.05)$ different from the adult by Student's $t$ test. $\ddagger$ Not detectable.

Table 2. Phospholipid composition of microvillus membranes of the newborn and adult rat proximal small intestine*

\begin{tabular}{|c|c|c|}
\hline \multirow[b]{2}{*}{ Phospholipid class } & \multicolumn{2}{|c|}{ Microvillus membrane } \\
\hline & Newborn & Adult \\
\hline & \multicolumn{2}{|c|}{ \% total lipid-phosphorus } \\
\hline Phosphatidylcholine & $44.4 \pm 1.4 \dagger$ & $34.6 \pm 1.8$ \\
\hline Phosphatidylethanolamine & $26.0 \pm 1.8$ & $28.4 \pm 2.6$ \\
\hline Phosphatidylinositol & $3.6 \pm 0.4 \dagger$ & $7.4 \pm 0.5$ \\
\hline Phosphatidylserine & $7.0 \pm 0.5$ & $6.8 \pm 0.8$ \\
\hline Sphingomyelin & $7.6 \pm 0.4$ & $8.0 \pm 0.6$ \\
\hline Lysophosphatidylcholine & $3.3 \pm 0.9$ & $4.0 \pm 0.6$ \\
\hline Phosphatidic acid & $1.7 \pm 0.4$ & $2.5 \pm 0.5$ \\
\hline Diphosphatidylglycerol & $2.2 \pm 0.2$ & $2.6 \pm 0.4$ \\
\hline Phosphatidylglycerol & $1.6 \pm 0.2$ & $1.4 \pm 0.4$ \\
\hline Lysophosphatidylethanolamine & $2.5 \pm 0.6$ & $2.8 \pm 0.7$ \\
\hline
\end{tabular}

* Values are means $\pm \mathrm{SE}$ of four membrane preparations.

$\uparrow$ Significantly $(p<0.05)$ different from the adult. 
saturated fatty acids $(14: 0+16: 0+18: 0)$ nor the proportion of arachidonate $(20: 4)$ was significantly different between newborn and adult MVM.

Changes in the phospholipid fatty acid pattern of MVM. To further determine if the changes in the total lipid fatty acid pattern of MVM reflected specific changes in individual phospholipid classes, fatty acids were selectively analyzed in phosphatidylcholine, phosphatidylethanolamine, and phosphatidylinositol. Table 4 shows the fatty acid composition of these three phospholipid classes in newborn and adult MVM. The data indicate that individual membrane phospholipid classes exhibited a distinct fatty acid pattern. In both MVM preparations, phosphatidylcholine contained relatively more palmitate than stearate, whereas phosphatidylethanolamine and phosphatidylinositol contained much more stearate than palmitate. The major unsaturated fatty acid in phosphatidylcholine was linoleate, whereas the major unsaturated fatty acid in both phosphatidylethanolamine and phosphatidylinositol was arachidonate. Similar to the finding in the total lipids of MVM, the major differences between the newborn and the adult appeared to be an increased ratio of $18: 1$ to $18: 2$ and an increased ratio of $16: 0$ to $18: 0$ in the newborn for all three phospholipid classes analyzed in this study.

\section{DISCUSSION}

The data in this newborn rat study and other previous studies in 2-wk-old suckling rats (26) and rabbits (27) as well as in aging rats (28) all indicate that there are developmental changes in the MVM lipid composition from birth to adulthood and also changes with aging. The changes differ, depending on the region of the gut, species, age of the animal, lipid classes measured, and

Table 3. Fatty acid composition of total lipids in microvillus membranes of newborn and adult proximal small intestine*

\begin{tabular}{ccc}
\hline \multirow{2}{*}{$\begin{array}{c}\text { Fatty acids } \\
\text { in total lipids }\end{array}$} & \multicolumn{2}{c}{ Microvillus membrane } \\
\cline { 2 - 3 } & Newborn & Adult \\
\hline $14: 0$ & $2.0 \pm 0.6$ & $0.9 \pm 0.4$ \\
$16: 0$ & $26.2 \pm 1.6 \dagger$ & $19.5 \pm 1.6$ \\
$16: 1 \omega 7$ & $4.0 \pm 0.2 \dagger$ & $2.0 \pm 0.3$ \\
$18: 0$ & $10.1 \pm 0.3 \dagger$ & $22.5 \pm 2.3$ \\
$18: 1 \omega 9$ & $27.4 \pm 1.3 \dagger$ & $18.4 \pm 1.7$ \\
$18: 2 \omega 6$ & $16.7 \pm 1.6 \dagger$ & $23.0 \pm 1.3$ \\
$20: 4 \omega 6$ & $10.0 \pm 1.0$ & $10.8 \pm 1.6$ \\
$18: 1 / 18: 2$ & $1.6 \pm 0.2 \dagger$ & $0.8 \pm 0.1$ \\
$16: 0 / 18: 0$ & $2.6 \pm 0.1 \dagger$ & $0.9 \pm 0.1$ \\
\hline
\end{tabular}

$*$ Values are means $\pm \mathrm{SE}$ of four membrane preparations.

$\dagger$ Significantly $(p<0.05)$ different from the adult. also possibly depending on the adaptive response to environmental factors.

Herein we demonstrate several specific differences in MVM lipids and phospholipids between the newborn and adult rats. First, the proximal membrane of the newborn contained much larger amounts of both total phospholipids and cholesterol per $\mathrm{mg}$ of MVM protein than the adult, but at the same time maintained a molar ratio of these two lipid classes similar to that of the adult. Similar findings were previously noted in MVM of newborn rabbits (3) and 2-wk-old suckling rats (26). The increased lipid/protein ratio may be related to the previously reported increased membrane fluidity in the newborn intestine of rats (4) and rabbits (3).

Second, the immature MVM from newborns was relatively rich in phosphatidylcholine, but poor in phosphatidylinositol as compared to mature MVM from the adult animals. A decreased phosphatidylinositol level was also found in the jejunal MVM of the 2-wk-old suckling rats (26), and a decreased level of tissue myo-inositol was found in the newborn rat intestine (29). The basis of this decrease is not clear.

Third, fatty acid patterns of phosphatidylcholine, phosphatidylethanolamine, and phosphatidylinositol in the newborn were different from that in the adult MVM preparations. Specifically, these changes in the phospholipid fatty acid side chains were an increased ratio of palmitate $(16: 0)$ to stearate $(18: 0)$ for saturated fatty acids and an increased ratio of oleate (18:1) to linoleate $(18: 2)$ for unsaturated fatty acids in the individual MVM phospholipid classes in newborn rats. Previously, Dobiasova et al. (30) reported that developmental changes in the fatty acid composition of intestinal phospholipids did not reflect changes in the composition of the diet.

However, one of the possible explanations of such fatty acid changes might be an increased lipogenesis which synthesizes 16:0 as the end product, combined with a concomitant increase in the activity of stearoyl-CoA desaturase which catalyzes the formation of 18:1 from 18:0. This type of fatty acid changes in the membrane phospholipid of small intestine can be induced by reducing the dietary intake of linoleate (31) which is an essential fatty acid for animals and humans. Thus, it is possible that differences in the phospholipid fatty acid pattern between newborn and adult intestines may be an adaptive response of intestine to different nutritional conditions, although a possible agerelated effect still cannot be excluded. The changes in both the polar head groups and the chain length and degree of saturation of fatty acids in individual phospholipid species may have a cumulative effect on the lipid contribution to membrane fluidity (6).

Phosphatidylinositol has a unique biochemical function not shared by other membrane phospholipids. It is involved in the production of two second messengers, inositol trisphosphate and diacylglycerol, for cellular signal transduction $(10,11)$. Although

Table 4. Fatty acid composition of major phospholipid classes in microvillus membrane of newborn and adult rat proximal small

\begin{tabular}{|c|c|c|c|c|c|c|}
\hline \multirow[b]{2}{*}{ Fatty acid } & \multicolumn{2}{|c|}{ Phosphatidylcholine } & \multicolumn{2}{|c|}{ Phosphatidylethanolamine } & \multicolumn{2}{|c|}{ Phosphatidylinositol } \\
\hline & Newborn & Adult & Newborn & Adult & Newborn & Adult \\
\hline $14: 0$ & $1.0 \pm 0.2$ & $0.5 \pm 0.4$ & $1.3 \pm 0.6$ & $0.8 \pm 0.7$ & $2.9 \pm 2.2$ & $1.1 \pm 1.7$ \\
\hline $16: 0$ & $35.3 \pm 5.3$ & $29.2 \pm 5.4$ & $22.6 \pm 3.1 \dagger$ & $14.8 \pm 2.4$ & $17.0 \pm 1.8 \dagger$ & $12.9 \pm 1.5$ \\
\hline $16: 1 \omega 7$ & $3.9 \pm 0.7$ & $1.4 \pm 0.9$ & $3.0 \pm 0.9 \dagger$ & $0.8 \pm 0.3$ & $0.7 \pm 0.2$ & $1.2 \pm 0.5$ \\
\hline $18: 0$ & $18.6 \pm 0.6 \dagger$ & $26.8 \pm 2.6$ & $35.4 \pm 7.5$ & $41.5 \pm 7.3$ & $44.1 \pm 7.6$ & $52.7 \pm 9.3$ \\
\hline $18: 1 \omega 9$ & $15.7 \pm 1.0 \dagger$ & $10.2 \pm 0.6$ & $14.0 \pm 1.6$ & $10.3 \pm 2.0$ & $6.5 \pm 0.8$ & $8.9 \pm 2.0$ \\
\hline $18: 2 \omega 6$ & $12.0 \pm 1.4 \dagger$ & $23.6 \pm 5.3$ & $5.7 \pm 2.9 \dagger$ & $12.9 \pm 2.3$ & $1.5 \pm 0.5 \dagger$ & $6.8 \pm 1.5$ \\
\hline $20: 4 \omega 6$ & $11.8 \pm 3.2$ & $7.0 \pm 3.0$ & $17.9 \pm 4.3$ & $15.1 \pm 5.7$ & $24.7 \pm 6.0$ & $17.3 \pm 3.2$ \\
\hline $18: 1 / 18: 2$ & $1.3 \pm 0.1 \dagger$ & $0.4 \pm 0.1$ & $2.5 \pm 0.6 \dagger$ & $1.3 \pm 0.3$ & $4.8 \pm 0.9 \dagger$ & $1.3 \pm 0.7$ \\
\hline $16: 0 / 18: 0$ & $1.9 \pm 0.3 \dagger$ & $1.0 \pm 0.1$ & $0.8 \pm 0.2 \dagger$ & $0.4 \pm 0.1$ & $0.4 \pm 0.1 \dagger$ & $0.2 \pm 0.1$ \\
\hline
\end{tabular}

* Values are means \pm SE of 4 membrane preparations.

$\dagger$ Significantly $(p<0.05)$ different from the adult. 
the influence of an altered phosphatidylinositol content in MVM on the disturbance of intestinal receptor function is not apparent, it is possible that a relative phosphatidylinositol deficiency might affect the responsiveness of the newborn intestine to external stimuli due to an interference with transmembrane signaling.

Another unique function of phosphatidylinositol is its role in the anchoring of certain glycoproteins to cell surface membranes (12). For example, alkaline phosphatase represents such a glycoprotein $(32,33)$. Our recent study has shown that phosphatidylinositol depletion is associated with a reduction in the activity of alkaline phosphatase in gerbil intestine in vivo (34). These findings may help explain why there were parallel changes between the levels of phosphatidylinositol and the activity of alkaline phosphatase in the newborn and adult MVM of the rat intestine (see Tables 1 and 2).

The intestinal epithelial surface serves as a protective barrier to prevent the penetration of a variety of pathogens and antigens that cause infection and infammation (35-37) or disrupt intestinal absorption and secretion (38). Recent studies (39) from our laboratory suggest that the barrier function of the small intestine appears to be incompletely developed at birth and during the preweaning period, and may thereby contribute to a disturbance in mucosal defenses perhaps accounting for the increased incident in intestinal and systemic disease in newborns.

The data in this study provide further evidences for the compositional basis of barrier immaturity in the developing intestine, showing that alterations in phospholipid composition were noted in the newborn MVM, and that specific lipid changes occurred at the molecular level. On the one hand, qualitative and quantitative changes in MVM lipids and phospholipids as well as lipid-protein distribution might alter membrane fluidity and organization. On the other hand, changes in phosphatidylinositol availability and molecular species might interfere with receptorlinked signal transduction and intestinal transport processes. Collectively, these intestinal surface changes may contribute in part to the increased MVM permeability, a mucosal barrier dysfunction in the neonate.

\section{REFERENCES} 1. Henning SJ 1985 Ontogeny of enzymes in small intestine. Annu Rev Physiol
47:231-245

2. Henning SJ 1987 Functional development of gastrointestinal tract. In: Johnson LR (ed) Physiology of the Gastrointestinal Tract, Vol 1. Raven Press, New York, pp 285-300

3. Pang KY, Bresson JL, Walker WA 1983 Development of the gastrointestinal barrier. III. Evidence for structural differences in microvillus membranes from newborn and adult rabbits. Biochim Biophys Acta 727:201-208

4. Pang KY, Bresson JL, Walker WA 1983 Development of the gastrointestinal barrier. V. Comparative effect of calcium binding on microvillus membrane structure in newborn and adult rats. Pediatr Res 17:856-861

5. Udall JN, Pang KY, Fritze L, Kleinman RE, Walker WA 1981 Development of the gastrointestinal mucosal barrier. I. The effect of age on intestinal permeability to macromolecules. Pediatr Res 15:241-244

6. Lands WWM, David FS 1984 Fluidity of membrane lipids. In: Kates M, Mason LA (eds) Biomembranes, Vol 12, Membrane Fluidity. Plenum Press, New York, pp 475-515

7. Sandermann H Jr 1978 Regulation of membrane enzymes by lipids. Biochim Biophys Acta 515:209-237

8. Brasitus TA, Schacter D, Mamouneas TG 1979 Functional interactions of lipids and proteins in rat intestinal microvillus membranes. Biochemistry 18:4136-4144

9. Green DE, Fry M, Blondin GA 1980 Phospholipids as the molecular instruments of ion and solute transport in biological membranes. Proc Natl Acad Sci USA 77:257-261

10. Berridge MJ 1984 Inositol trisphosphate and diacylglycerol as second messengers. Biochem J 220:345-360

11. Berridge MJ, Irvine RF 1984 Inositol trisphosphate, a novel second messenger in cellular signal transduction. Nature 312:315-321

12. Low MG, Ferguson MAJ, Futerman AH, Silman I 1986 Covalently attached phosphatidylinositol as a hydrophobic anchor for membrane proteins. Trends Biochem Sci 1 1:212-215

13. Buckley JT, Hawthorne JN 1972 Erythrocyte membrane polyphosphoinositide metabolism and the regulation of calcium binding. J Biol Chem 247:72187223

14. Nishizuka Y 1984 The role of protein kinase C in cell surface signal transduction and tumor promotion. Nature 308:693-698

15. Hauser H, Howell K, Dawson RMC, Bowyer DE 1980 Rabbit small intestinal brush border membrane preparation and lipid composition. Biochim Biophys Acta 602:567-577

16. Koldovsky O, Asp NG, Dahlqvist A 1969 A method for the separate assay of "neutral" and "acid" $\beta$-galactosidase in homogenates of rat small-intestinal mucosa. Anal Biochem 27:409-418

17. Dahlqvist A 1968 Assay of intestinal disaccharidases. Anal Biochem 22:99107

18. Kessler M, Acuto D, Storelli G, Murer H, Semenza GA 1978 A modified procedure for the rapid preparation of efficiently transporting vesicles from small intestinal brush border membranes. Their use in investigating some properties of D-glucose and choline transport systems. Biochim Biophys Acta 506:136-154

19. Lowry OH, Rosebrough NJ, Farr AL, Randall RG 1951 Protein measurement with the Folin phenol reagent. J Biol Chem 193:265-275

20. Folch J, Lees M, Sloane-Stanley GH 1957 A simple method for the isolation and purification of total lipids from animal tissue. J Biol Chem 226:497509

21. Rudel LL, Morris MD 1973 Determination of cholesterol using $o$-phthalaldehyde. J Lipid Res 14:364-366

22. Turner JD, Rouser G 1970 Precise quantitative determination of human blood lipids by thin-layer and triethylaminoethylcellulose column chromatography. II. Plasma lipids. Anal Biochem 38:437-445 23. Bartlett GR 1959 Phosphorus assay in column chromatography. J Biol Chem
$234: 466-468$

24. Chu SW, Hegsted DM 1981 Assessment of the essential fatty acid requirement in gerbil by polyunsaturated fatty acid ratio. $J$ Nutr 111:1548-1555

25. Forstner GG, Tanaka K, Isselbacher KJ 1968 Lipid composition of the isolated rat intestinal microvillus membrane. Biochem J 109:51-59

26. Schwarz SM, Hostetler B, Ling S, Mone M, Watkins JB 1985 Intestinal membrane lipid composition and fluidity during development in the rat. Am J Physiol 248:G200-G207

27. Schwarz SM, Ling S, Hostetler B, Draper JP, Watkins JB 1984 Lipid composition and membrane fluidity in the small intestine of the developing rabbit.
Gastroenterology 86:1544-1551

28. Brasitus TA, Yeh KY, Holt PR, Schachter D 1984 Lipid fluidity and composition of intestinal microvillus membranes isolated from rats of different ages. Biochim Biophys Acta 778:341-348

29. Burton LE, Wells WW 1976 myo-Inositol metabolism during lactation and development in the rat. The prevention of lactation-induced fatty liver by dietary myo-inositol. J Nutr 106:1617-1628

30. Dobiasova M, Hahn P, Koldovsky O 1964 Fatty acid composition in developing rats. Fatty acid composition of triglycerides and phospholipids in some organs of the rat during postnatal development. Biochim Biophys Acta
$84: 538-549$

31. Chu SW, Hegsted DM 1980 Myo-inositol deficiency in gerbils: Changes in phospholipid composition of intestinal microsomes. J Nutr 111:1548-1555

32. Low MG, Finean JB 1978 Specific release of plasma membrane enzymes by a phosphatidylinositol-specific phospholipase C. Biochim Biophys Acta 508:567-570

33. Low MG, Zilvermist DB 1980 Role of phosphatidylinositol in attachment of alkaline phosphatase to membranes. Biochemistry 19:3913-3918

34. Chu SW, Geyer RP, Walker WA 1987 myo-Inositol action on gerbil intestine: alterations in alkaline phosphatase activity upon phosphatidylinositol depletion and repletion in vivo. Biochim Biophys Acta 929:220-225

35. Virnig NL, Reynolds JW 1974 Epidemiological aspects of neonatal necrotizing enterocolitis. Am J Dis Child 128:186-190

36. Soothill JF, Stokes CR, Turner MV, Norman AP, Taylor B 1976 Disposing factors and the development of reaginic allergy in infancy. Clin Allergy 6:305-319

37. Sanberg DH, McIntosh RM, Bernstein CW, Carr R 1977 Severe steroidresponsive nephorosis associated with hypersensitivity. Lancet 1:388-391

38. Guerrant RL 1985 Microbial toxins and diarrhoeal diseases: introduction and overview. In: Evered D, Whelan J (eds) Microbial Toxins and Diarrhoeal Disease. Ciba Foundation Symposium 112, Pitman, London, pp 1-13

39. Walker WA 1985 Role of the mucosal barrier in toxin/microbial attachment to the gastrointestinal tract. In: Evered D, Whelan J (eds) Microbial Toxins and Diarrhoeal Disease. Ciba Foundation Symposium 112, Pitman, London,
pp 35-56 